The Philosophical Quarterly 67 (2017): 813-834. (please cite published version)

\title{
Epistemology Personalized
}

\section{Matthew A. Benton}

Epistemology has focused primarily on propositional knowledge, that is, on how it is we can know true propositions, where propositions represent the world as being a certain way, and when true, what is known is simply that the world is a certain way. Thus what is known is the structure of the objective world, that is, of some mind-independent truths, where the paradigm is that of sensory perception. The only kind of knowledge that would be mind-dependent in any sense would be knowledge of the contents of someone's mind. Since it is plausible to think of a mind as part of the world to be known, and since one cannot know the content of a mind unless the mind contains that content, both realism and the factivity of knowledge are upheld even where such truths are in some sense mind-dependent.

The present essay considers an underexplored area of epistemology, namely knowledge of persons, and how interpersonal knowledge seems different from knowledge of propositions. If propositional knowledge is a state of mind, ${ }^{1}$ consisting in a subject's attitude to a (true) proposition, the account to be developed here thinks of interpersonal knowledge as a state of minds, involving a subject's attitude to another (existing) mind. As shall be seen, this kind of knowledge exhibits a gradability characteristic of context-sensitivity, and an analogue of factivity. Yet it also invokes an epistemology at odds with certain truisms of propositional epistemology, particularly with specific formulations of realism and mind-independence. ${ }^{2}$

\footnotetext{
${ }^{1}$ See especially Williamson (2000, and 2009: 293-301), and Nagel (2013).

${ }^{2}$ The early twentieth century realists emphasized, against the idealists, that 'knowing makes no difference to what is known,' and that 'knowing in no way alters or modifies the thing known': see Marion (2000: 307-8) on the Oxford Realists, citing Cook Wilson (1926) and Prichard (1909: 108, 118). Likewise, they stressed that the object of
} 
Propositional knowledge is arguably distinct in kind from both objectual and interpersonal knowledge. On the account to be developed here, interpersonal knowledge is had when two subjects know each other personally, as subjects, from the second-person perspective. ${ }^{3}$ It requires that one have had personal encounters of reciprocal causal contact; that interpersonal knowledge is symmetric; and that it is not a form of, or reducible to, propositional knowledge. In §1 I motivate the distinction between propositional knowledge and objectual knowledge, of which interpersonal knowledge is a type. $\$ \S 2-3$ outline three grades of personal involvement, through which we can more carefully distinguish propositional knowledge about persons from what it is to know someone personally; and I develop the interesting features of the third grade of involvement which make for interpersonal knowledge. $\S_{4}$ applies interpersonal knowing to several issues in epistemology and social philosophy, especially its role in understanding evidential position, testimony, and religious epistemology. Along the way I also consider the relevance of such knowledge for moral obligations generally, and for our understanding of friendship.

\section{Knowing Persons, Objects, Propositions}

Linguistic data support the broad distinction between objectual and propositional knowledge, data which serve to isolate, in a prima facie way, interpersonal knowledge from propositional knowledge about persons.

Our languages encode a difference between propositional and other kinds of knowledge; and when we find such distinctions widespread across many languages, this is suggestive of something important to our cognitive lives. In English this distinction is encoded only grammatically: the construction ' $\mathrm{S}$ knows that $\phi$ ' is used to claim propositional

knowledge was not mind-dependent. But interpersonal knowledge as sketched here is in an important sense mind-dependent, and it crucially does make a difference to what is known.

3Compare Price (1969: 50-4), Dalmiya (2001), Matheson (2010), Stump (2010: chs. 3-4), and especially Talbert (2015); in \$3 I shall note similarities and differences with her account. For recent developments on second-person relations in philosophy and related disciplines, see Eilan (2014). 
knowledge, whereas 'S knows NP', where 'NP' is a noun phrase such as a proper name or definite description, can be used to indicate that $\mathrm{S}$ knows personally the person referred to by the noun phrase or name. These grammatical rules require a well-formed indicative sentence to follow a 'that' clause, which expresses the proposition claimed to be known. But one cannot insert only a noun-phrase or name after such a 'that' clause: in English, for example

\section{(1) \# Susan knows that John. ${ }^{4}$}

In contrast to English, many languages have distinct lexical items for personal knowledge and for propositional knowledge: in Spanish, there are saber and conocer; in German, kennen and wissen; in French, connaître and savoir. This lexical distinction isn't limited to Indo-European languages, for similar terms are found in Semitic and Sino-Tibetan languages. ${ }^{5}$ In such languages, one cannot acceptably use the propositional verb when speaking of knowing a personal acquaintance (or knowing a city, for example); nor can one acceptably use the acquaintance verb when speaking of knowledge one has of someone, or some place, with which one has no first-hand experience.

These distinctions only mark off objectual knowledge from propositional knowledge, and the thought so far has been that interpersonal knowledge is a kind of objectual knowledge. But there is additional evidence that supports a distinctively interpersonal kind of knowledge, namely, from conjunctive tests of univocal meaning, and from substitution behaviour with names and definite descriptions.

${ }^{4}$ Of course there is a demonstrative use of such a sentence, which typically intones on 'that': e.g. in a conversation someone might ask if Susan knows John where there is more than one person named John salient, and upon clarifying which John the asker has in mind, one could say 'Susan knows that John'.

${ }^{5}$ For example modern Hebrew (makir and yada), and Chinese (Mandarin and Cantonese: rènshi and zhídao). For discussion of the Polish wiedzieć and znać, see Wierzbicka (2002: 93-6) and Goddard (2007: 14). 


\subsection{Univocality and Conjunction Tests}

In linguistics, the possibility of reducing two full statements into an elided conjunction provides a standard test for semantic sameness: ${ }^{6}$ if you saw a (mammalian) bat, and I saw a baseball bat, we couldn't express this with the sentence, 'We both saw a bat'. ${ }^{7}$ Likewise, the sentence

(2) Jim went to the bank, and Alexa, too.

cannot be used to express the proposition that Jim went to a financial institution and Alexa went to a riverbank. By contrast,

(3) Jack knows that the Cubs won and he knows that the Red Sox won.

can be reduced to either of the following

(3a) Jack knows that the Cubs and Red Sox won.

(3b) Jack knows that the Cubs won, and the Red Sox, too.

which reflects the intuitive idea that knowing that $p$ and knowing that $q$ entails knowing that: $p \& q .^{8}$

However, the two meanings of 'know' in (4) cannot be reduced to (4a):

(4) Hannah knows that penguins waddle, and Ted knows John.

(4a) \# Hannah knows that penguins waddle, and Ted, John.9

\footnotetext{
${ }^{6}$ For Stanley \& Williamson (2001: 430-1), passing such tests (conjoining embedded questions and 'that' complements under ' $k$ now') is evidence that knowledge-how is a form of knowledge-that. See Chomsky (1957: 36) for his original conjunction rule.

${ }^{7}$ Cf. Zwicky \& Sadock (1975: 18).

${ }^{8}$ That is, the converse of the Distribution principle given in Hawthorne (2004: 41).

${ }^{9}$ Stanley \& Williamson (2001: 436-7). (2) and (4a) exhibit (attempts at) 'gapping' (an ellipsis rule which permits deletion of an identical verb from one or more clauses to the right of a clause containing the same verb), whereas ( 3 b) exhibits 'stripping' (an ellipsis rule which permits deleting everything in a clause under identity with corresponding parts of a preceding clause, except for one constituent): see Hankamer \& Sag (1976: 40811). Stripping is often regarded as a form of gapping, and gapping as an instance of
} 
Indeed, reduced conjunctions like (4a) are not possible in languages like French that use distinct lexical terms for propositional knowledge and personal/objectual knowledge, precisely because one lexical item (e.g. savoir) cannot do double duty for the other (connaitre). These results are widely recognised to show that the meaning of propositional 'know[s]' differs from that of personal/objectual 'know[s]'.

Yet it has gone unnoticed that similar data is available for distinguishing between subtypes of objectual knowledge. Objectual knowledge in the broadest sense picks out the knowledge relation of one's first-hand familiarity with a field of study, a city, or a person, among others. This relation is not univocal when it undergoes such conjunction reduction under the 'know[s]' verb. One test, bare argument ellipsis or stripping, permits reduction by deleting from a later clause all the corresponding identical parts of a preceding clause, except one constituent:

(5) Elise knows Boston and Elise knows London.

(5a) Elise knows Boston, and London, too.

A similar test is gapping (see fn. 9):

(6) Elise knows Boston and Evan knows London.

(6a) Elise knows Boston, and Evan, London.

As we might expect, interpersonal knowledge attribution permits stripping as well as gapping:

(7) Marge knows John and Marge knows Barry.

(7a) Marge knows John, and Barry, too.

conjunction reduction: Hankamer (1973: 27); cf. Jackendoff (1971) for dissent. 
(8) Marge knows John and Helen knows Barry.

(8a) Marge knows John, and Helen, Barry.

But stripping and gapping can seem less acceptable when they combine different knowledge relations:

(9) \# Jason knows philosophy, and Boston, too.

(10) \# Duncan knows Edinburgh, and Lisa, physics.

(11) \# Jane knows that the Yankees won, and Tim, too.

(Where the intended reading of (11) is not that Tim also knows that the Yankees won, but that Jane also knows Tim.) These examples strongly suggest that the propositional knowledge relation is distinct from the personal knowledge relation; they may also suggest distinct subtypes within the broader objectual knowledge relation. Arguably, stripping and gapping are not permitted in these conjunction reductions because they attempt to group different knowledge relations under one verb. At the very least, positing a distinctive interpersonal knowledge relation would explain both the acceptability of conjunction reduction in (7a) and (8a), as well as the unacceptability of reduction in (4a) or (11). Note also that comparative judgements between knowledge relations can sound unacceptable, especially when one is propositional:

(12) \# Jason knows Boston better than the piano.

(13) \# Elise knows Susan better than that the Yankees won.

All these results suggest that the sense of 'knows' invoked by propositional, objectual, and interpersonal constructions is not univocal.

However the data and the coordination requirements that might be suggested by them are more complicated than this. For one can acceptably reduce a conjunction that conjoins objectual knowledge, for example of a city, with objectual knowledge of a person or group, at least where the 
latter is related to the former:

(14) Walter knows London, and its people.

(15) Walter knows London, and its Lord Mayor.

So apparently there is not simply a blanket prohibition against coordinating across types of knowledge. It might be that the examples (14)-(15) are permitted precisely because the way in which one would gain first-hand familiarity with one of the objects is regarded as a standard way of also gaining objectual knowledge of the other: for example, experiencing London first-hand is also a way of getting to know its people. On the other hand, there might be pragmatic constraints of a Gricean sort that explain why some conjunction reductions are unacceptable. As such, any broader lessons to be drawn from the above data about individuating the full range of knowledge relations will have to be tentative at best.

\subsection{Substitution Behaviour}

Though the conjunction reduction tests above are merely suggestive, a difference in the substitution behaviour of propositional and interpersonal knowledge ascriptions is more decisive.

First, note that the 'S knows NP' construction can take a propositional use and an interpersonal use. When used with a name (e.g. ' $R$ '), 'S knows $\mathrm{R}$ ' is often used as short-hand for ' $\mathrm{S}$ knows of $\mathrm{R}$ ' or ' $\mathrm{S}$ knows who $\mathrm{R}$ is'. ${ }^{10}$ These constructions pick out S's propositional knowledge about $\mathrm{R}$ by which $\mathrm{S}$ might identify or describe $\mathrm{R},{ }^{11}$ for example in answer to the question 'Who is R?' Accordingly, this use of ' $S$ knows $R$ ' ascribes 'knowledge- $w h$ ', where the '-wh' complement embeds a question; it thus ascribes propositional knowledge, and can be distinguished from the interpersonal-acquaintance sense of knowledge, which does not embed such questions (see Stanley 2011: 36-7). This is supported by the fact

\footnotetext{
${ }^{10}$ As in: 'I know Smith, he's the guy who... but I don't know him personally.'

${ }^{11}$ Such propositions known about $\mathrm{R}$ can be flagged by what Donnellan (1966: §3) called the referential use of a definite description in an assertion.
} 
that one can claim knowledge-who while disavowing interpersonal knowledge:

(16) I know who Rebecca is, but I don't know her personally.

(17) I know of Rebecca, but I don't know her. ${ }^{12}$

Similarly, with knowledge-wh: you might know Paris (by experience) but not know which is the largest city in France; conversely, you might know which city is the largest in France without knowing it from experience.

Differences in substitution behaviour emerge from comparing propositional knowledge characteristic of knowledge-who with interpersonal knowledge. The interpersonal knowledge relation plausibly preserves truth under substitution of co-referential terms. Taking ' knows $_{i}$ ' to stand for interpersonal knowledge: if Lisa knows ${ }_{i}$ Will, and Will $=$ Liam, then Lisa also knows ${ }_{i}$ Liam (though she may not know that he is called Liam). But the propositional knowledge underlying knowledge-who does not work this way. If Lisa knows who Will is, and Will = Liam, it does not follow that Lisa also knows who Liam is: the propositional knowledge by which Lisa knows how to identify Will won't suffice for her to identify Liam unless Lisa also knows that Will $=$ Liam.

Similar results ensue with definite descriptions. If Mark knows ${ }_{i}$ Sue, and Sue is the department chair, then Mark knows ${ }_{i}$ the department chair, even if Mark is unaware that Sue is the department chair. But the propositional knowledge of knowledge-who does not preserve truth under substitution: if Mark knows who Sue is, and Sue is the department chair, then it does not follow that Mark knows who is the department chair.

The data from substitution behavior distinguish propositional knowledge-who (and knowledge-of) from interpersonal knowledge. The latter is not easily reducible to propositional knowledge, nor to some kind of 'qualitative' knowledge of 'what it is like': sentences such as

\footnotetext{
${ }^{12}$ Hintikka (1970: 878-83) seems to ignore this distinction, though he acknowledges that 'first-hand knowledge of people and things'... 'is much less clearly defined than the framework created by one's perceptual point of view or one's personal memories.'
} 
(18) She knows many people.

(19) She knows him.

appear (on their default reading) to predicate an interpersonal knowledge of others, which does not seem like the relation of propositional knowledge or knowledge of some qualitative experience. ${ }^{13}$

Thus the 'S knows NP' construction can refer to either facts known about a person (knowledge-who or knowledge-of), or to the relation of knowing someone personally. Similarly, some of what we often call 'personal knowledge' consists simply in propositions known about persons; whereas other knowledge referred to by that phrase is distinctively nonpropositional because interpersonal. Because of this ambiguity, we must distinguish three grades of personal involvement in order to isolate the interpersonal knowledge of interest here.

\section{Three Grades of Personal Involvement}

The first and second grades of personal involvement delineated in what follows are ways of acquiring propositional knowledge about a person. Though the third grade of involvement is also a way to acquire propositional knowledge about someone, it makes available something more: interpersonal knowledge, which itself is arguably irreducible to propositional knowledge.

\footnotetext{
${ }^{13}$ Some-call them 'intellectualists' - may object that personal knowing just reduces to propositional knowledge of a certain kind, and may insist that the personal 'know[s]' construction applies only when one has propositional knowledge of a particular kind, or gained a particular way. Against this, note that such an intellectualist will need to explain why the standard semantic tests (conjunction reduction and the substitution behaviour from $\S_{1}$ ) differentiate between the two constructions if they both refer to propositional knowledge. These tests reveal distinct syntactic constraints on propositional 'know' and personal 'know', which is the opposite of what we would expect if they both referred to propositional knowledge. Additionally, the intellectualist will need to explain what seems to have been lost in the amnesiac, death, and biographer cases considered in $\S 3$ below. For these reasons, I regard the intellectualist line to be unpromising.
} 
The first grade of personal involvement is achieved by having propositional knowledge of facts about a person, gained without first-hand experience of the person. $\S 1$ mentioned first-hand familiarity with a person or a city; I shall say that an experience (of a personal subject, or of some perceptual object) is first-hand only if it is of the subject/object itself, and thus not mediated by transmission through another mind. ${ }^{14}$ Propositional knowledge about someone that is not first-hand is usually gained secondhand, by testimonial chains, from others: thus one can know 'by description' all manner of facts about someone through, say, reading newspapers or hearing about them from friends, rather than first-hand by interacting with the person themself. One typically learns the names and roles of many people in this second-handed way. Thus first grade knowing about someone is propositional knowledge of facts about them, acquired by some other method (typically testimony) than first-hand experience of the person.

The second grade of personal involvement is had when one gains propositional knowledge about a person through perceptual access to the person (though it need not be perception of the person 'in the flesh'). Such facts are learned first-hand, and the causal direction is one-way, from the person to the knower. Various types of knowledge are available in this second grade: objectual, qualitative, as well as propositional knowledge. Of course, one can acquire a kind of objectual knowledge by perceiving a person, just as one can acquire a kind of objectual knowledge by perceiving an object (and this may bring with it some qualitative knowledge of what a person or object looks like). But one can plausibly acquire either of these without thereby gaining propositional knowledge about the object. For example, visually, one can see a maple tree without seeing that it is a maple tree (Dretske 1969: ch. 1). Given this distinction between objectual seeing and propositional seeing, being perceptually related to

\footnotetext{
${ }^{14}$ Nor mediated by explicit inference of the kind used in existential instantiation. For one could gain knowledge by description in a way that is neither first-hand nor secondhand: if you let 'Tom' name the world's tallest person, you can know, based on induction, that Tom is over 7 feet tall, though you presumably have never been in causal contact with Tom (cf. a case considered by Strawson 1963: ch. 1). Though this technically falls under our first grade, because this knowledge seems uninteresting I shall ignore it here.
} 
objects can give one a primitive kind of objectual knowledge through perceptual acquaintance, particularly if one can commit the qualitative experience to (episodic) memory. ${ }^{15}$ In the same way, one might have objectual knowledge of persons which does not yield propositional knowledge about them; but one might also learn a lot of propositions about someone through perceiving them. Our main interest in this second grade is the acquisition of propositional knowledge about someone through perceptual access to them.

Neither of the first two grades of personal involvement suffice for knowing someone personally. Consider the following case: Juan and Julia go to the same large committee meetings over many years. They know each other's names and institutional roles, and know many other facts about each other; but they know all this from other sources, or by overhearing conversations each is having with other people. They hear each other offer suggestions in meetings, but they've never addressed each other individually in conversation. They have much first and second grade knowledge (propositional, qualitative, objectual) of each other. But intuitively, Julia and Juan do not know each other personally.

Thus the third grade of personal involvement requires treating another subject as a subject, that is, as an 'I' treats as an individual 'you'. To enter the third-grade of involvement, there must minimally be at least one subject treating the other as another subject, and thus there can be onesided third-grade involvement without it rising to the level of knowing each other interpersonally. The paradigm case of such involvement, however, is first-hand and distinctively interpersonal, where each treats the other as a subject with the aim of reciprocation. ${ }^{16}$ Because of these reciprocal interactions, interpersonal knowledge is plausibly a state of minds,

\footnotetext{
${ }^{15}$ Compare Campbell (2002), Martin (2002; 2004), and Brewer (2011) on perceptual acquaintance. In the terms of Russell's early taxonomy, objectual knowledge (and something like interpersonal knowledge as distinguished below) would be knowledge of things had directly by acquaintance (Russell 1998 [1912]: 25-8; cf. also 1910), where the 'thing' is another mind.

${ }^{16}$ Some might be inclined to ascribe one-sided third-grade treatment as enabling someone to know another 'personally'; but I regard these ascriptions as faulty, and parasitic on features of genuinely interpersonal knowing where the paradigm is reciprocal third-grade involvement.
} 
requiring engagement with another subject as a subject. We refer to such knowledge when we talk of knowing someone 'personally'.

Interpersonal knowledge is autonomous relative to any particular propositions known about a person, in this sense: for any set of propositions one knows about someone, one could know that someone interpersonally without knowing those propositions about them. ${ }^{17}$ And interpersonal knowledge is distinguished from the first and second grades of personal (propositional) knowledge in that the former requires that the causal route is two-way, running both directions between subjects. While second grade involvement might include two-way perceptual interactions (as in the case of Juan and Julia), to create interpersonal knowledge this two-way causal interaction must be undertaken from the second-person perspective: minimally, this second-person stance involves each person treating the other as a subject, for example in the language of address, or in joint attention to objects or topics of conversation. ${ }^{18}$

Whereas we noted above that one might acquire objectual knowledge of someone by standing in a perceptual relation to their mind (and thereby be able to gain propositional knowledge characteristic of the second grade of involvement), to have interpersonal knowledge those perceptual relations must run both ways between minds who each adopt a secondpersonal perspective toward one another. ${ }^{19}$ When I speak of interpersonal knowledge, I have both directions of this third grade in mind.

In the spirit of Russell's 'direct acquaintance,' Sosa notes that knowing a person requires an acquaintance-like perceptual contact:

Knowing someone or something, knowing some 'object' in the broadest sense of this term, seems at least sometimes to require

\footnotetext{
${ }^{17}$ Moreover, one could know any set of propositions about someone without knowing them personally. Consistent with all this, interpersonal knowing might always bring with it some propositional, qualitative, or objectual knowledge.

${ }^{18}$ For second-personal approaches, see Eilan (2014), Lavin (2014), Longworth (2014), and Salje (forthcoming). For work on joint attention and mirror neurons in the perception of other minds, see Eilan et al. (2005), Stump (2010: ch. 4), and Green (2012), among others.

${ }^{19}$ Note that Price's (1969: 54-5) and Stump's (2010: ch. 3) accounts of personal knowing are not fine-grained enough to distinguish between the Juan/Julia case above and those who meet this third grade of personal involvement.
} 
some kind of special causal interaction with that 'object'. This is plausibly a requirement for knowing a person, and for knowing an experience or a sight, say the sight of the Boston skyline two miles from the south on highway 93, or the experience of a cold shower after a hard run. ${ }^{20}$

Borrowing from these ideas, I shall say that one is interpersonally acquainted with other persons by learning facts from them first-hand: when one knows another interpersonally, at least some learning about them occurs second-personally, in 'I-you' subject-to-subject interaction. When interpersonal, some of what one learns about others is learned from, because it is given to one by, the persons themselves. As Talbert puts it in her own account, 'the other must consent to be known' (Talbert 2015: 203). By interacting in this way with other persons, we stand in perceptual acquaintance relations with their minds, even though such personal interactions are of course mediated by sense-perception, inference, and so on. Thus 'directness' is reconstrued as resulting from subject-to-subject (typically face-to-face) encounters, which as noted earlier, are first-hand in the sense that the experiencing of another's mind is not mediated by transmission through someone else's mind. Thus interpersonal knowledge's acquaintance cannot be had at second-hand, for that would be a way of indirectly knowing propositions about a person, rather than a way of knowing someone personally. ${ }^{21}$

\section{Knowing One Another}

On the account sketched so far, interpersonal knowledge is a state of minds, requiring second-personal encounter(s) with someone. These conditions are captured by the following necessary conditions, where 'knows ${ }_{i}$ 'abbreviates 'interpersonally knows':

\footnotetext{
${ }^{20}$ BonJour \& Sosa (2003: 100).

${ }^{21}$ Craig (1991: 143ff.), and Matheson (2010: 439ff.) criticize direct, 'acquaintancelike' perceptual requirements for knowing persons. Because I do not require in the flesh perceptual contact for my account, such criticisms do not apply.
} 
ENCOUNTER: $S$ knows $i$ R only if (i) $S$ has had reciprocal causal contact with $\mathrm{R}$, in which (ii) $\mathrm{S}$ treats $\mathrm{R}$ second-personally, and (iii) $\mathrm{R}$ treats $\mathrm{S}$ second-personally.

I noted earlier that interactions taken from the second-person perspective minimally involve treating another as a subject, for example in the language of address or in joint attention to topics of conversation or to objects in the vicinity. More specifically, I shall say that a treatment by a subject $\mathrm{S}$ toward its recipient $\mathrm{R}$ is second-personal in virtue of $\mathrm{S}$ treating $\mathrm{R}$ as a subject (that is, with the intentional stance as an 'I' toward an individual agent as a singular 'you') where: S offers to R some of S's own thoughts, words, attitudes, or emotions, and $\mathrm{S}$ is or for the most part intends to be attentive to R's thoughts, words, attitudes, or emotions which might be given (to $\mathrm{S}$ as 'you') in return. ${ }^{22}$ Such contact between them is reciprocal insofar as each shares with the other some of their own thoughts, words, attitudes, or emotions in response to the other. We might say that such reciprocal encounters bring the mind of the known subject itself right into the subjective life of the knower's mind, ${ }^{23}$ and thus their occasion for interpersonal knowing is, as our gloss has it, a state of minds meeting.

It will be helpful to compare briefly the present account with Talbert's (2015) second-person framework for knowing others. For Talbert, such interactions are constituted by 'shared worlds' and shared interactions between two persons, where the breadth and depth of such interactions contribute to how well they know each other. Talbert's notion of 'secondperson knowledge' is irreducible to propositional knowledge given its dependence on each subject's skill, which develops into an individualized knowledge-how, that is, knowledge of how to interact with particular persons, deployed in the service of experiencing both their mind and sharing experiences along with that mind. My account emphasizes many similar

\footnotetext{
${ }^{22}$ As noted earlier, we can allow for one-sided third-grade of involvement, corresponding to when a subject $S$ treats $R$ second-personally, but $R$ either does not even receive it as such, or R does not reciprocate such treatment to $S$; thus a case where (ii) holds but not (iii). While we can allow for this possibility, such a one-sided interaction will not rise to the level of involvement needed to achieve interpersonal knowledge.

${ }^{23}$ To borrow Campbell's phrase: Campbell (2002: 6); cf. also Campbell (2005).
} 
features, though I prefer to locate the irreducibility of interpersonal knowing in the two-way interactions characteristic of two subjects treating each other as subjects. ${ }^{24}$ In addition, as we shall see below, Talbert's four conditions target a different phenomenon-knowing someone well—whereas our present aim is an account of the minimal conditions required to gain interpersonal knowledge at all (a phenomenon which Talbert does not explicitly consider). Finally, it is unclear that her four conditions for the interactions needed to know some one well are able to deliver the judgement that Juan and Julia, in the case considered in the last section, fail to know each other personally.

ENCOUNTER's clauses (ii) and (iii) capture why distant spies or stalkers would not count as knowing their target personally, even though they may acquire much (second grade) propositional knowledge about them: though they may have second-grade knowledge of the person, they will not (if distant) be treating their target second-personally, nor will their targets so treat them. Compare also a biographer, who learns many facts about the person she is researching. We can suppose that in principle such a biographer could come to know more propositions about him than even he himself knew. Yet this biographer would not, given just that propositional knowledge, counting as knowing him personally; indeed, if he is dead and they never could have met, she would agree that she lacks an important kind of knowledge about him. The reason why is that none of ENCOUNTER's three clauses are fulfilled.

EnCOUnTER's clause (i) is not redundant given (ii) and (iii), because the latter conditions can be met without fulfilling the former. Suppose that Maud writes a letter to someone, Jim, whom she has never met or interacted with. Coincidentally, Jim also writes a letter to Maud. But neither letter is received by the other (perhaps this is repeated, with letters never being received). Arguably clauses (ii) and (iii) are fulfilled, but not (i); and intuitively, they do not yet know each other personally. ${ }^{25}$ Relatedly for the

\footnotetext{
${ }^{24}$ In part because I want to remain neutral here on the reducibility of know-how to knowledge-that. See e.g. Stanley 2011.

${ }^{25}$ This judgement remains intuitive if each letter is received and read, but neither Jim nor Maud respond to the other's letter. Notice that becoming acquainted with a fictional character by reading a novel involves a kind of contact with both the 'mind' of
} 
case of an intercepted letter: if Peter receives Maud's letter addressed to and intended for Jim, he does not thereby come to know Maud personally, nor does Maud come to know Peter personally (mutatis mutandis for, say, a conversational eavesdropper). In this case, none of clauses (i)-(iii) are fulfilled. ${ }^{26}$ In short, fulfilling ENCOUNTER ensures that the causal contact is reciprocal and taken up under second-personal terms.

Such encounters can be technologically mediated, and still be 'meetings of the minds' in our first-hand sense. Thus two people could interpersonally know each other entirely as pen pals or phone pals or chat room pals, ${ }^{27}$ though in these extreme cases, they would lack a standardly available knowledge-who: they would not visually recognise one another (except by sharing pictures), nor would they have qualitative knowledge of mannerisms, facial expressions, mood patterns, and so on. ${ }^{28}$ For mature subjects, interpersonal knowledge typically brings with it at least some knowledge-who by which the known person can be individuated, and once had, at least some of this knowledge-who must be retained in order to keep knowing interpersonally. This pragmatic fact can explain why it sounds strange to claim interpersonal knowledge in the present tense but effectively disavow (all salient) knowledge-who, as in:

(20) \# I know Robert personally, but I don't know who he is. ${ }^{29}$

the character, plus the mind of the author; but there is no reciprocation, nor (I take it) does the reader treat the character or author second-personally, and thus ENCOUNTER is failed. Contrast Stump's (2010: chs. 3-4) account, which allows one to know (personally) a fictional character.

${ }^{26}$ What about the case of a speaker/lecturer to a large group? The speaker takes a broader second-person (plural) perspective toward other persons, but the attentiveness and reciprocation from the audience (even if there is $\mathrm{Q} \& \mathrm{~A}$ ) is minimal and when present, it is very one-sided; and so arguably, in some cases, either clause (i) or (iii) (or both) are not fulfilled.

${ }^{27}$ For more, see Talbert (2013).

${ }^{28}$ In such cases, a version of (20) might be apt to convey that one lacks a particularly salient kind of knowledge-who.

${ }^{29}$ Of course, having isolated a relevant kind of knowledge-who, one can make similar disavowals. This is especially clear in the past tense: 'I knew Robert personally, but I didn't know who he was [the famous actor]'. Thanks to Tim Williamson here. 
Thus in typical cases, interpersonal knowing brings with it a great stock of qualitative knowledge and knowledge-who, and normally enough such that each subject will recognise that they've had the personal encounters which make possible their interpersonal knowing. But any mutual recognition of this is not itself necessary for interpersonal knowledge. ${ }^{30}$

The encounters which enable one (for the near future) to have interpersonal knowledge also enable one to get to know someone more fully. One can know someone more or less well, and thus interpersonal knowledge is gradable, admitting of degrees. This gradability makes for third-person comparative judgements, whose default reading tends to be that of interpersonal knowledge rather than propositional knowledge:

(21) John knows Sue better than Rachel does. (Stanley 2005: 38)

Thus one can know someone more intimately not just by adding to one's stock of propositional knowledge about him or her, but by having more personal contact with them, by sharing experiences. As a result, there plausibly is a context-sensitive threshold for how well S knows R, or how often $\mathrm{S}$ and $\mathrm{R}$ have had personal interactions, in order for $\mathrm{S}$ to count, in a given context, as knowing $\mathrm{R}$ personally. In some contexts knowing someone interpersonally requires more than just having met once: one will have had face-to-face personal contact on several occasions in the not too distant past. ${ }^{31}$ But in other contexts, even when one hasn't met someone multiple times, one can in principle still count as knowing someone: 'Do you know R?' 'Yes, I just met her for the first time yesterday.' And in still other contexts, where the interpersonal knowledge attributed is of someone who has celebrity status or is otherwise very busy, the standard for

\footnotetext{
${ }^{30}$ I want to allow that, for example, infants can personally know their caregivers, even though they presumably lack the propositional recognition typical of more mature subjects. For related work on joint attention in infants, see Roessler (2005); for the idea that pre-linguistic children can engage in distinctively second-personal ways of interacting, see Heal (2014: 322). Contrast Matheson (2010: 443), whose account has it that knowing personally requires that the known person be aware (know) that she has communicated personal information about herself to the knower.

${ }^{31}$ For if one hasn't seen or talked to someone one knew for many years, then at some point she is someone that one merely 'once knew'.
} 
what it takes to know them can be raised quite high: for example, one may not count as knowing Barack Obama personally simply by having met and interacted with him several times. Because my main interest here is in specifying the minimal conditions on knowing someone personally, I shall set aside the issue of what more might be needed to know someone well (for an apt account, see Talbert 2015: 194-200).

Through personal encounters, people can progress from being mere acquaintances to being friends, to close friends, to intimates or lovers. Progressing through such stages would be difficult without personal contact of the kind envisioned. Increase in personal encounters, once there are enough of them, make for interpersonal knowing. ${ }^{32}$ And arguably one must continue to have enough recurring encounters over time in order to keep knowing someone personally (indeed, as shown by Talbert (2015: 198f.), knowing someone well plausibly requires a certain breadth and depth of interactions). Given the importance of such two-way interactions, interpersonal knowledge is plausibly also symmetric:

Symmetry: $\mathrm{S}$ knows $i$ R only if $\mathrm{R} \mathrm{knows}_{i} \mathrm{~S}$.

S's knowing $R$ interpersonally requires that $R$ also interpersonally know S. Symmetry does not require that persons know one another on the same levels of intimacy: $\mathrm{S}$ might know $\mathrm{R}$ much better than $\mathrm{R}$ knows $\mathrm{S}$, but this may not affect the fact that they do know one another interpersonally. There are diachronic difficulties concerning when interpersonal knowledge begins and ends; so far we have only considered necessary conditions on interpersonal knowing, where retaining interpersonal knowledge requires retaining at least some propositional, qualitative, or objectual knowledge gained about the subject. Yet sufficient conditions for interpersonal knowing might be impossible to come by. Here I only note that Symmetry is committed to the interpersonal knowledge between $\mathrm{S}$ and $\mathrm{R}$ being lost for both if it is lost for one.

This seems to get right cases of amnesia, where $\mathrm{R}$ remembers nothing

\footnotetext{
${ }^{32}$ Saying how much is enough is a vexed matter (compare propositional knowledge and how much evidence/justification it takes).
} 
(having lost all qualitative and propositional knowledge) of S, but where $\mathrm{S}$ still has a lot of propositional knowledge about R. In such cases, it is plausible to say that $\mathrm{S}$ no longer knows $\mathrm{R}$ interpersonally, but retains most of his propositional knowledge about $\mathrm{R}$, including how $\mathrm{S}$ had come to know $\mathrm{R}$ personally through various first-hand interactions. It also rightly predicts cases of death: we no longer know a dead subject interpersonally, thus we shift to the past tense with interpersonal 'know' ('I knew her well'), though not for propositional 'know' ('I know that she loved cats'). Thus Symmetry also captures a condition that mimics the factivity of propositional knowledge: to know another interpersonally, there must be a mind there to be known. ${ }^{33}$ Finally, Symmetry is supported by the way that interpersonal knowledge ascriptions standardly license various inferences. For example, self-ascribing interpersonal knowledge typically licenses the inference that they also know you; nor is the inference obviously cancellable: 'I know Beth, but she doesn't know me.' Moreover, common social expectations suggest that a speaker will rightly hesitate to claim to know someone if she suspects that they would not themselves affirm that they know her. Because she is liable to mislead her conversational partners by claiming to know that person, her hesitation is plausibly due to the standard inference available to them that the person in question would also know her.

One might worry that the prospects for acquiring interpersonal knowledge are threatened under conditions of deception, though neither $\mathrm{EN}_{-}-$ COUnter nor Symmetry rule this out. Suppose that through many personal encounters Conrad, a conman, is constantly misrepresenting himself to Beatrice. Beatrice has adopted many beliefs about Conrad, most of which are false. On the one hand, it might seem that Beatrice doesn't really know Conrad at all. Yet on the other hand, it seems that Beatrice still knows someone interpersonally (namely Conrad), even when Beatrice learns that it is a manipulated relationship built upon deceit; I think we should accept this latter line. The judgement that Conrad knows Beatrice

33Note that this feature of my view differs from Stump's view of Franciscan knowledge, for on her view one can know (personally) deceased individuals and fictional characters (Stump 2010: 53). 
personally while Beatrice does not know Conrad personally is plausibly driven by the disproportionate amount of propositional knowledge which Conrad has of Beatrice but which Beatrice in turn lacks for Conrad. It also might track the fact that Beatrice meets some sincerity conditions for Conrad to know her well (see Talbert's sincerity condition: 2015: 194), but not vice versa. ${ }^{34}$ If so, the conman case suggests that one can gain and retain interpersonal knowledge even without gaining (much) propositional knowledge of the subject; whereas the amnesiac and death cases suggest that one can retain all one's propositional knowledge of a subject while losing one's interpersonal knowledge of them. ${ }^{35}$

The moral dimensions raised by the conman case can lead us to consider other cases bearing on moral philosophy more generally; but instead of allowing moral judgements to affect whether there is interpersonal knowledge, we may ask whether interpersonal knowing can affect moral judgements. For example, arguably the presence or absence of interpersonal knowledge can illuminate the widespread ethical intuition that we often have (defeasibly) stronger moral obligations to those we know and are close to than to others. ${ }^{36}$ If knowing someone personally involves having a minimal level of acquaintance and familiarity with that person, this may generate obligations owing to that knowledge. Indeed, such knowledge could be pressed into service for those who find second-personal relations to be central to moral obligation. 37 At the very least, personal encounters can have a positive impact on our moral behaviour toward those individuals: some empirical findings suggest that eye-contact character-

${ }^{34}$ Arguably the conman case only causes a problem for an account which takes SymmETRY and ENCOUNTER to be jointly sufficient conditions for interpersonal knowledge, and I have not argued for their sufficiency. (Indeed, I suspect that adequate necessary and jointly sufficient conditions are, as in much of philosophy, too difficult to come by.)

35 Recall that intellectualists (like Matheson 2010) who think of interpersonal knowing as reducible to having enough propositional knowledge gained in a certain way (e.g. through personal encounters) will have to offer a rival explanation of (i) why the linguistic data exhibit substitution differences between knowledge-who and interpersonal knowledge, and (ii) what seems lost or missing in the amnesiac, death, and biographer cases considered above. Whether it would be a better explanation of these than the account offered here, I will leave to others to judge.

${ }^{36}$ See e.g. Unger (1996: ch. 2) and Kamm (2007: chs. 10-11).

37E.g. Darwall (2006; 2013a; 2013b). 
istic of EnCOUNTER and our third grade of personal involvement leads to more civil and moral behaviour toward those individuals, compared with merely knowing someone's name (knowledge-who typical of our first grade) or with seeing the person (characteristic of our second grade of personal involvement). ${ }^{38}$ Whether or not we do in fact have stronger moral obligations toward individuals we know personally, marshalling an account of interpersonal knowledge promises to shed some light on why one might act more appropriately toward, or feel that one has stronger obligations towards, those personally known.

\section{Further Applications}

The last section briefly sketched some ways that an account of interpersonal knowledge might contribute to moral philosophy. Its contribution to everyday areas of our social lives is perhaps obvious. 39 Here I shall consider its role in epistemology and social philosophy, in particular, to debates over evidence, friendship, religious epistemology, and testimony.

If interpersonal knowledge is as sketched above, then some knowledge which is not knowledge of propositions can nevertheless figure in a support relation and can interact with propositional evidence. ${ }^{40}$ The general idea is this. When one knows another interpersonally, one can be entitled to trust or rely on that person in some ways, not simply because one has evidence that the person is trustworthy or reliable with respect to some (or any) domain, but solely because one has a certain kind of relationship with that person. Alternatively, when one knows someone interpersonally, one may be entitled to distrust or eschew reliance on that person, not because one possesses particular evidence that the person is untrustworthy or unreliable with respect to some domain, but solely because one knows this person by way of personal interactions.

\footnotetext{
${ }^{38}$ In a study amongst strangers in online communications: Lapidot-Lefler \& Barack (2012).

${ }^{39}$ E.g. interpersonal knowledge (past or present) plays an important role in perhaps the most famous results in sociology: see Granovetter (1973: 1361, incl. n. 4).

${ }^{40} \mathrm{I}$ shall assume, for the moment, that evidence is propositional; cf. Williamson (2000: ch. 9) and Dougherty (2011).
} 
This idea can be made more vivid thus. Suppose two people, Jill and Sam, can have the same evidence (let's say, they each know propositions $p_{1}-p_{n}$ ) bearing on Tom's expressed commitment to $\phi$ at (about) time $t$ and his reliability in following through on his word. Let us say that this evidence justifies Jill and Sam to the same degree in believing that Tom will $\phi$ at around $t$ (or if one prefers, it justifies the same credence). Suppose that $t$ rolls around and Jill and Sam realize that Tom has not yet $\phi^{\prime}$ d. If Jill knows Tom personally, this knowledge can make Jill both rational and justified in continuing to believe (or retain the same credence), at least for some appropriate length of time, that Tom will nevertheless fulfil his commitment to $\phi$ (especially if we suppose that Tom's commitment was to Jill that he would $\phi$ ). By contrast, if Sam does not know Tom personally, Sam will not be rational and justified in continuing to believe (retain her credence), for the same duration as Jill, that Tom will fulfil his commitment to $\phi$. That is, even though they have the same evidence $\left(p_{1}-p_{n}\right)$ bearing on Tom's commitment and reliability concerning his $\phi$-ing, ${ }^{41}$ there will be some later time $t_{2}$ at which Jill but not Sam will be rational and justified in continuing to believe, despite the mounting evidence that Tom has shirked his commitment. ${ }^{42}$ But if so, then (propositional) evidence isn't the only justifier of belief; interpersonal knowledge can play such a role, just as it may play a role in facilitating or hindering the acquisition of propositional knowledge. (I shall also consider a testimony case shortly.) And to the extent that interpersonal knowledge is crucial to the above case, it also promises to shed light on the parallel issue of epistemic partiality in friendship (see Keller 2004, Stroud 2006, and Lackey unpub): if one can be entitled to believe in or trust a friend in some matter beyond what the evidence on its own makes rational, this will likely be in part because interpersonal knowledge is playing a crucial role.

${ }^{41}$ For those who doubt the possibility that Jill and Sam could both know $p_{1}-p_{n}$ while only Jill (and not Sam) knows Tom interpersonally, note that Sam could learn $p_{1}-p_{n}$ through Jill's testimony that: $p_{1}-p_{n}$.

${ }^{42}$ Notice how appealing to interpersonal knowledge can adequately answer questions about epistemic credentials in such cases. Jill can respond to the question (perhaps posed by Sam), 'Why, under these circumstances, do you continue to believe Tom will $\phi$ ?' with 'Because I know Tom'. Likewise, Sam can justify her failing to believe (or her reduced credence) that Tom will come through by citing that she does not know Tom personally. 
One might doubt that in the above case Jill really is better off in any distinctively epistemic way than Sam, given that they possess the same propositional knowledge relevant to whether Tom will keep his commitment. And one might doubt this even while agreeing that there is some sense in which Jill is more entitled to think that Tom will keep his commitment. Why should we suppose that if Jill is more entitled, in some sense, to think so, that this is because the factor in play (namely interpersonal knowledge) is of some epistemic import? Here is a reason to think that the factor is indeed epistemically significant. In some situations we rightly care about whether a person has had direct perceptual acquaintance with the facts or with some event, and the kind of qualitative support which that gives to the person puts them in an epistemically stronger position. Consider cases concerning isolated second-hand knowledge: one knows some proposition yet didn't learn it first-hand, but rather second-hand by way of testimony. In such cases, we often judge that though the person indeed knows, she is not as strongly situated as the first-hand knower to assert or act (properly) upon that knowledge (see Lackey 2011 and Benton 2016). Similarly, in criminal court cases a lawyer will prefer to call an eye-witness, who can claim to have seen someone at a crime scene; or a character witness, who knows personally an accused individual. What these witnesses have in common is first-hand acquaintance (either perceptual or interpersonal) with the individual in question; the lawyer would be far less interested in someone who knows all the same facts about an event or an individual but knows them entirely by learning such facts from another's say-so. Our preferences about these cases suggest that it matters how one knows what or whom one knows, where the mode of learningfirst-hand-is less subject to doubt or memory failure. 43 Clearly then, first-hand acquaintance is valued by us in large part because it improves the knower's epistemic position. Since much of what is distinctive about interpersonal knowing is the first-hand manner of interpersonal involvement with another subject, we should expect that it is Jill's interpersonal

43It also may bring with it additional richness of content that can be the source of further recollection or identification: e.g. the qualitative knowledge needed to identify someone from a police lineup. 
knowledge of Tom which makes her more entitled to think he will come through. Knowledge, not just of propositions but of persons, can enhance one's epistemic position; but this is unsurprising, since knowledge can have epistemic effects. ${ }^{44}$

Can the view offered here, that interpersonal knowledge can sometimes play a role akin to that of evidence, be squared with the spirit of Williamson's $\mathrm{E}=\mathrm{K}$ thesis, that one's evidence is all and only one's knowledge? In the above case, Jill and Sam possess the same propositional evidence, but possess different knowledge. One can perhaps retain the spirit of $\mathrm{E}=\mathrm{K}$, given that interpersonal knowledge is a kind of knowledge; thus if $\mathrm{E}=\mathrm{K}$, even (non-propositional) knowledge can serve as evidence, particularly if it entails certain propositions (in our case, knowing $_{i}$ $\mathrm{R}$ entails that $\mathrm{R}$ exists). Going this revisionary route would require dropping the claim that all evidence is propositional (Williamson 2000: 193ff.), in favour of the claim that all evidence is knowledge; thus the schematic argument for $\mathrm{E}=\mathrm{K}$ would instead be (where the first premise would require supplementary argument):

All evidence is knowledge.

All knowledge is evidence.

All and only knowledge is evidence.

Even if one balks at this route, because as non-propositional, such knowledge is ill-suited to enter into evidential probability relations, there remains an indirect way it could contribute to one's evidential standing: when one has knowledge that one has interpersonal knowledge, this known proposition can presumably play the relevant evidential role.

A similar theme concerning evidence and interpersonal knowledge has occasionally been appealed to in religious epistemology. ${ }^{45}$ If God exists

\footnotetext{
${ }^{44}$ No doubt there is more to be said here about the conditions that justify trust over mistrust; but my focus here is on the epistemological side of these matters.

45See Kierkegaard (1992 [1846]: 199-200), James (1912: 23, 27), Mitchell (in Flew and MacIntyre 1955: 103-5), Mitchell 1973: 140), Lewis (1955; see Wielenberg 2008: 158ff. for discussion), Rawls (2009 [1942]: 112-9 and 224ff.), and esp. Stump (2010),
} 
and one can (in some relevant way) know God as a personal subject, then this will affect how the believer ought to respond to the general problem of divine hiddenness, or to other specific evidence suggesting that God does not exist, does not love her, or has abandoned God's promises. If interpersonal knowledge between subjects matters in a distinctively epistemic way to evidence that bears on that relationship, this may sanction a kind of dogmatism or steadfastness in the face of contrary evidence; but in the envisioned case, that sanction is provided not only by what, but by whom, one knows. Note also the sceptical scenario concerning the existence of God: even if God exists and one knows God interpersonally, utilizing a kind of closure principle ${ }^{46}$ to come to know that there is a God will depend on how hard it is to gain knowledge that one interpersonally knows God.

Finally, consider the role of interpersonal knowledge in testimony. There is much debate in the testimony literature over the conditions under which one is entitled to trust a testifier; and these considerations extend to the conditions under which one can acceptably trust the testimony of strangers (e.g. Lackey 2007: 352ff.). I submit that there is much to be gained by including in such assessments whether, and how well, one knows interpersonally an interlocutor. Surely it can make a difference to how entitled one is to accept someone's testimony whether, and how well, one personally knows the testifier (indeed, knowing certain persons can make it obligatory for one to refrain from trusting their testimony). Additionally, in many cases, whether one is in a position to come to know that $p$ when a speaker testifies that $p$ may depend on how well one knows that speaker. Yet the debates over testimony have been largely conducted without taking up this issue. ${ }^{47}$

who deploys her view of second-person knowledge in handling the problem of evil.

${ }^{46}$ For example, Closure: Necessarily, if $\mathrm{S}$ knows that $\mathrm{S}$ knows $i \mathrm{R}$, competently deduces $q$, and thereby comes to believe that $q$, while retaining knowledge that $S$ knows $s_{i} R$ throughout, then S knows that $q$ (cf. Hawthorne 2004: 34). In other work, I discuss the relevance of such principles for scepticism about the existence of other minds.

47Lackey (2008: ch. 8) broaches the topic, but portrays any appeal to interpersonal relationships in testimony as epistemically impotent. If the view I'm aiming at is correct, then interpersonal knowledge will have an epistemic effect on testimony; and it ought to, since knowledge has epistemic effects. McMyler (2011) and Faulkner (2014) consider 


\section{Conclusion}

Epistemology has been gripped by defining and examining propositional knowledge. Yet there is another familiar kind of knowledge, which has been largely neglected in epistemology, and which may be the first knowledge we have in our cognitive development: interpersonal knowledge. I do not claim to have fully articulated all the relevant contours of such knowledge here. The present paper takes some crucial first steps toward an account of interpersonal knowledge, by distinguishing it from other kinds of knowledge we have of other persons, and by exploring how interpersonal knowledge can be brought to bear on other philosophical debates..$^{8}$

Seattle Pacific University, USA

\section{References}

Benton, Matthew A. 2016. "Expert Opinion and Second-Hand Knowledge." Philosophy and Phenomenological Research 92: 492-508.

BonJour, Laurence and Sosa, Ernest. 2003. Epistemic Justification. Oxford: Blackwell.

second-personal accounts of testimony, but which nevertheless do not invoke anything about interpersonal knowledge. Small (2014) discusses the distinctiveness of learning from teaching; but because our teachers are often those whom we know personally, the topic stands to gain from the ideas developed here.

${ }^{48}$ For helpful discussion and comments, many thanks to Charity Anderson, Max Baker-Hytch, Billy Dunaway, Julien Dutant, David Efird, Kati Farkas, Lizzie Fricker, Anil Gomes, Adam Green, Brian Hedden, Jon Kvanvig, Maria Lasonen-Aarnio, Ofra Magidor, Patrick McDonald, Emil Moeller, Ted Poston, Duncan Pritchard, Dani Rabinowitz, Rebekah Rice, Blake Roeber, Jeff Russell, Leland Saunders, Ernie Sosa, Allison Krile Thornton, Chris Tucker, John Turri, Lee Walters, Timothy Williamson, and especially John Hawthorne; and to two helpful anonymous referees. Thanks also to audiences at the University of Innsbruck, the University of Edinburgh, the University of York, Baylor University, Oxford University, the University of Notre Dame, and Seattle Pacific University. This paper was also made possible through the support of a grant from the John Templeton Foundation. The opinions expressed in this publication are those of the author and do not necessarily reflect the views of the John Templeton Foundation. 
Brewer, Bill. 2011. Perception and its Objects. Oxford: Oxford University Press.

Campbell, John. 2002. Reference and Consciousness. Oxford: Oxford University Press.

- 2005. "Joint Attention and Common Knowledge." In Naomi et al. Eilan (ed.), Joint Attention: Communication and Other Minds, 287-297. Oxford: Clarendon Press.

Chomsky, Noam. 1957. Syntactic Structures. The Hague: Mouton.

Craig, Edward. 1991. Knowledge and the State of Nature: an Essay in Conceptual Synthesis. Oxford: Clarendon Press.

Dalmiya, Vrinda. 2001. "Knowing People." In Matthias Steup (ed.), Knowledge, Truth, and Duty, 221-234. Oxford: Oxford University Press.

Darwall, Stephen. 2006. The Second-Person Standpoint: Morality, Respect, and Accountability. Cambridge: Harvard University Press.

- 2013a. Honor, History, and Relationship: Essays in Second-Personal Ethics II. Oxford: Oxford University Press.

- 2013b. Morality, Authority, and Law: Essays in Second-Personal Ethics I. Oxford: Oxford University Press.

Donnellan, Keith. 1966. "Reference and Definite Descriptions." Philosophical Review 75 .

Dougherty, Trent. 2011. "In Defense of Propositionalism about Evidence." In Trent Dougherty (ed.), Evidentialism and its Discontents, 226-232. Oxford: Oxford University Press.

Dretske, Fred I. 1969. Seeing and Knowing. Chicago: University of Chicago Press.

Eilan, Naomi. 2014. “The You Turn.” Philosophical Explorations 17: 265-278.

Eilan, Naomi et al. (ed.). 2005. Joint Attention: Communication and Other Minds. Oxford: Clarendon Press.

Faulkner, Paul. 2014. "The Moral Obligations of Trust." Philosophical Explorations 17: $332-345$. 
Flew, Antony and MacIntyre, Alasdair (eds.). 1955. New Essays in Philosophical Theology. London: SCM Press.

Goddard, Cliff. 2007. "A Culture-Neutral Metalanguage for Mental State Concepts." In Andrea C. Schalley and Drew Khlentzos (eds.), Mental States, volume 2 of Language and Cognitive Structure, 11-35. Amsterdam/Philadelphia: John Benjamins Publishing.

Granovetter, Mark S. 1973. "The Strength of Weak Ties." American Journal of Sociology 78: 1360-1380.

Green, Adam. 2012. "Perceiving Persons." Journal of Consciousness Studies 19: 49-64.

Hankamer, Jorge. 1973. "Unacceptable Ambiguity." Linguistic Inquiry 4: 17-68.

Hankamer, Jorge and Sag, Ivan. 1976. "Deep and Surface Anaphora.” Linguistic Inquiry 7: 391-476.

Hawthorne, John. 2004. Knowledge and Lotteries. Oxford: Clarendon Press.

Heal, Jane. 2014. "Second Person Thought." Philosophical Explorations 17: 317331.

Hintikka, Jaakko. 1970. "Objects of Knowledge and Belief: Acquaintances and Public Figures." Journal of Philosophy 67: 869-883.

Jackendoff, Ray S. 1971. "Gapping and Related Rules." Linguistic Inquiry 2: 2135 .

James, William. 1912. The Will to Believe, and Other Essays in Popular Philosophy. Longmans, Green, and Co.

Kamm, F.M. 2007. Intricate Ethics: Rights, Responsibilities, and Permissible Harm. Oxford: Oxford University Press.

Keller, Simon. 2004. "Friendship and Belief." Philosophical Issues 33: 329-351.

Kierkegaard, Søren. 1992 [1846]. Concluding Scientific Postscript to Philosophical Fragments, volume 1. Princeton: Princeton University Press.

Lackey, Jennifer. 2007. "Why We Don't Deserve Credit for Everything We Know." Synthese 158: 345-361. 
- 2008. Learning from Words: Testimony as a Source of Knowledge. Oxford: Oxford University Press.

—. 2011. "Assertion and Isolated Second-Hand Knowledge." In Jessica Brown and Herman Cappelen (eds.), Assertion: New Philosophical Essays, 251-275. Oxford: Oxford University Press.

—. unpub. "Why There is No Epistemic Partiality in Friendship." Draft.

Lapidot-Lefler, Noam and Barak, Azy. 2012. "Effects of Anonymity, Invisibility, and Lack of Eye-Contact on Toxic Online Disinhibition." Computers in Human Behavior 28: 434-443.

Lavin, Douglas. 2014. "Other Wills: The Second-Person in Ethics." Philosophical Explorations 17: 279-288.

Lewis, C.S. 1955. “On Obstinacy in Belief.” The Sewanee Review 63: 525-538.

Longworth, Guy. 2014. "You and Me." Philosophical Explorations 17: 289-303.

Marion, Mathieu. 2000. "Oxford Realism: Knowledge and Perception I." British Journal for the History of Philosophy 8: 299-338.

Martin, M.G.F. 2002. "The Transparency of Experience." Mind and Language 17: $376-425$.

—. 2004. "The Limits of Self-Awareness." Philosophical Studies 120: 37-89.

Matheson, David. 2010. "Knowing Persons." Dialogue 49: 435-453.

McMyler, Benjamin. 2011. Testimony, Trust, and Authority. Oxford: Oxford University Press.

Mitchell, Basil. 1973. The Justification of Religious Belief. New York: Seabury Press.

Nagel, Jennifer. 2013. "Knowledge as a Mental State." Oxford Studies in Epistemology 4: 273-308.

Price, H.H. 1969. Belief. London: George Allen \& Unwin.

Prichard, H.A. 1909. Kant's Theory of Knowledge. Oxford: Oxford University Press. 
Rawls, John. 2009. A Brief Inquiry into the Meaning of Sin and Faith: with "On My Religion". Cambridge: Harvard University Press.

Roessler, Johannes. 2005. "Joint Attention and the Problem of Other Minds." In Naomi et al. Eilan (ed.), Joint Attention: Communication and Other Minds, 230259. Oxford: Oxford University Press.

Russell, Bertrand. 1910. "Knowledge by Acquaintance and Knowledge by Description." Proceedings of the Aristotelian Society 11: 108-128.

- 1998 [1912]. The Problems of Philosophy. Oxford: Oxford University Press, 2nd edition.

Salje, Léa. forthcoming. "Thinking About You." Mind .

Small, Will. 2014. "Teaching and Telling." Philosophical Explorations 17: 372-387.

Stanley, Jason. 2005. Knowledge and Practical Interests. Oxford: Clarendon Press.

- 2011. Know How. Oxford: Oxford University Press.

Stanley, Jason and Williamson, Timothy. 2001. "Knowing How." Journal of Philosophy 98: 411-444.

Strawson, P. F. 1963. Individuals. London: Methuen.

Stroud, Sarah. 2006. "Epistemic Partiality in Friendship." Ethics 116: 498-524.

Stump, Eleonore. 2010. Wandering in Darkness: Narrative and the Problem of Suffering. Oxford: Clarendon Press.

Talbert, Bonnie M. 2013. "Screened Conversations: Technologically Mediated Interactions and Knowledge of Other Minds." Techné 17: 333-349.

- 2015. "Knowing Other People: A Second-Person Framework." Ratio 28: $190-206$.

Unger, Peter. 1996. Living High and Letting Die: Our Illusion of Innocence. Oxford: Oxford University Press.

Wielenberg, Erik J. 2008. God and the Reach of Reason: C.S. Lewis, David Hume, and Bertrand Russell. Cambridge: Cambridge University Press. 
Wierzbicka, Anna. 2002. "Semantic Primes and Universal Grammar in Polish." In Anna Wierzbicka and Cliff Goddard (eds.), Meaning and Universal Grammar: Theory and Empirical Findings, volume 2, 65-144. Amsterdam/Philadelphia: John Benjamins Publishing.

Williamson, Timothy. 2000. Knowledge and its Limits. Oxford: Oxford University Press.

- 2009. "Replies to Critics." In Patrick Greenough and Duncan Pritchard (eds.), Williamson on Knowledge, 279-384. Oxford: Oxford University Press.

Wilson, John Cook. 1926. Statement and Inference, volume 1. Oxford: Clarendon Press.

Zwicky, Arnold M. and Sadock, Jerrold M. 1975. "Ambiguity Tests and How to Fail Them." In John P. Kimball (ed.), Syntax and Semantics, volume 4, 1-36. New York: Academic Press. 